\title{
Phonostylistic study of Spanish-speaking politicians: Populist vs. Conservative
}

Carmen Patricia Pérez

CLILLAC-ARP, Université Paris Diderot - Paris 7, France

https://doi.org/10.36505/ExLing-2016/07/0032/000291

\begin{abstract}
Conservative and Populist politicians can be easily recognized thanks to their phonostyle characterized by specific prosodic patterns. In this study, I analyzed four politicians' phonostyle in public 'spontaneous' speeches: Hugo Chavez (HC), José D. Ortega (JO), José R. Zapatero ( $\mathrm{Z}$ ) and Enrique Peña (EP). The acoustic analysis suggests that two main types of phonostyles can be found: a populist's phonostyles ( $\mathrm{HC}$ and $\mathrm{JO})$ and a conservative one ( $\mathrm{Z}$ and $\mathrm{EP})$.
\end{abstract}

\section{Introduction}

Conservative and populist politicians have a particular and typical way of speaking, their own 'phonostyle(s)', varying according to the different 'phonogenres' (specific conditions of productions such as interview, public speech, etc.). They are easily recognizable by the public. Studies on French politicians show that it is thanks to prosodic features such as prominence, acceleration, register change, breaks, etc. (Fónagy 1983; Duez 1997; Touati 1995; Léon 1993; Martin 2012). I will describe the prosodic features used by 4 Spanish-speaking politicians in public 'spontaneous' speeches: H. Chávez (Venezuela), J. Ortega (Nicaragua), J. Zapatero (Spain) and E. Peña (Mexico). This study is purely phonostylistic; I consider that the differences observed are due to the social and political backgrounds and not to the different varieties of spoken Spanish (Sosa 1999; Hualde \& Prieto 2015).

\section{Methodology}

\section{Corpus}

The 4 realizations illustrated below come from 'spontaneous' public speeches delivered by the 4 politicians. They may be considered as representative of each speaker.

\section{Intonation model}

The interpretation of the prosodic analysis is based on Ph. Martin's model "Incremental Prosodic Structure" (1975-2015), where rising and falling contours do contrast indicating a relation of dependency between them, triggered by the following contours, firstly the final one of the

ExLing 2016: Proceedings of $7^{\text {th }}$ Tutorial and Research Workshop on Experimental Linguistics, 27 June - 2 July 2016, Saint Petersburg, Russia 
utterance. These contours are developed on prosodic words (aka accent phrases, group of one or more words with only one stressed syllable). They are described as follow: C0: Fall (very low) on the last stressed syllable and eventually on the following unstressed syllables to signal the end of an utterance; C1: Rise, above the glissando threshold (see the glissando formula in Rossi 1971, correlated with the speed of the melodic change); C2: Non-final falling contour, above the glissando threshold; Cn: 'Neutralized', i.e. slightly rising or falling, with a shortened vowel, below glissando threshold; Cc: fall-rise, flat or slightly falling on the stressed syllable and rising on the following unstressed one(s). $\mathbf{C h}$ is phonetic, used by HC; it falls very low ('high dive' and lengthening on the last syllable) at the end of each intonation phrase (IP).

\section{Acoustic analysis}

After an initial perceptual analysis (Pérez 2014), the four politicians were classified in two different groups: populist (HC and JO) and conservative ( $\mathrm{Z}$ and $\mathrm{EP}$ ).

\section{Populist Phonostyle: Hugo Chávez and José Ortega}

$\mathrm{HC}$ and JO's utterances are divided into short chunks separated by long pauses. The last one ends with a $\mathrm{C} 0$; the preceding ones finish with a $\mathrm{C} 1$ on the penultimate stressed syllable of a word (Spanish frequent word stress pattern), followed by a Ch, a spectacular 'high dive' of about sixteen semitones on the last unstressed syllable, which is nearly twice as long as the stressed vowel. This is the phonetic marker of HC's phonostyle, as he does it in a regular way. When 'Ch' contours do not fall very low they can be considered as continuation contours (-*).

To interpret the prosodic structure, we need several levels hierarchy. At the top level, it is an enumeration of $\mathrm{C} 1+\mathrm{Ch}$ all contrasting with $\mathrm{C} 0$. At lower levels, there may be $\mathrm{C} 1, \mathrm{Cn}$ and $\mathrm{C} 2$ contours contrasting between them, with restrained melodic movements, but not depending on the final $\mathrm{C} 0$. This structure does not seem to be congruent with the syntactic-semantic structure as contours are regularly similar. In this way, the IPs could be analyzed like autonomous utterances.

JO's realizations are less marked and less regular than HC's ones.

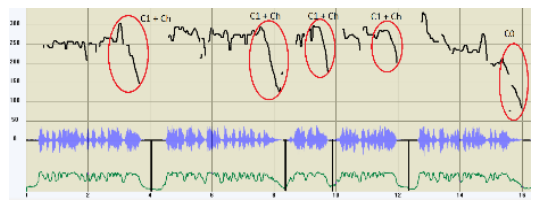

Figure 1. Chávez in public speech.

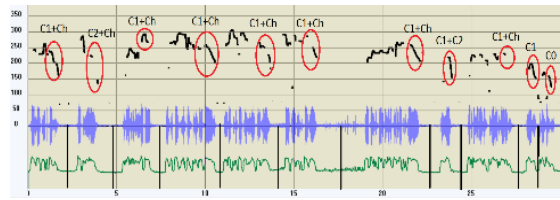

Figure 2. Ortega in public speech. 


\section{Conservative Phonostyle: J. Zapatero and E. Peña}

Here also speeches are segmented into short chunks; for Z, almost all the contours end with a rising contour (C1) on the penultimate syllable, going most of the times higher on the last unstressed syllable but sometimes there are C2 or Cn contours. Z's utterance seems to be an enumeration with similar C1's (all pertaining to the top level) that contrast with the final $\mathrm{C} 0$, but inside the IP there are slope contrasts with less melodic movements.

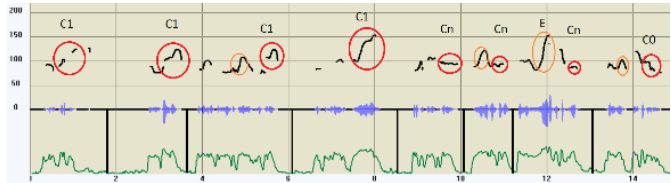

Figure 3. Zapatero in public speech.

For EP, the contour frequently employed is also C1 on the stressed syllable with a following unstressed syllable seldom rising but most of the time falling a little (but never like $\mathrm{HC}$ or JO). In the prosodic structure there is more contrast at the top and lower levels hierarchy.

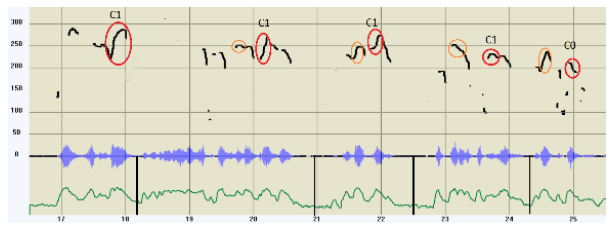

Figure 4. Peña in public speech.

\section{Discussion and conclusion}

The acoustic analysis suggests that two main types of phonostyles can be found: a populist phonostyles (HC and JO) and a conservative phonostyles ( $Z$ and EP). These phonostyles differ in similar speech situations ('phono genre'), mainly in (1) the realization of the final Intonation Phrase (IP) contours (see figure 5), (2) the F0 range and (3) the lengthening at the end of the IP. (1) In HC and JO, there is a F0 rising on the stressed syllable followed by a 'high dive' while Z's contours are most of the time made of a rise on the stressed syllable continuing with a rise to a higher F0 value. It could be noticed that EP is perceived as close to $\mathrm{Z}$, but his contour is most of the time rising on the stressed syllable and falling a little on the following one(s). (2) the F0 range is wider for the 'populist' phonostyle than for the 'conservative' one (while the average F0 is similar: $250 \mathrm{~Hz}$ ). (3) the lengthening at the end of the IPs, is very frequent in 'populist' phonostyles and not at all present in 'conservative' phonostyles. Furthermore, the speech rate is 
similar and the IP construction is of the same type: speeches are generally segmented into small chunks (IP) and there is a resetting at the beginning of the IPs (not in $\mathrm{Z}$ pattern).

FO

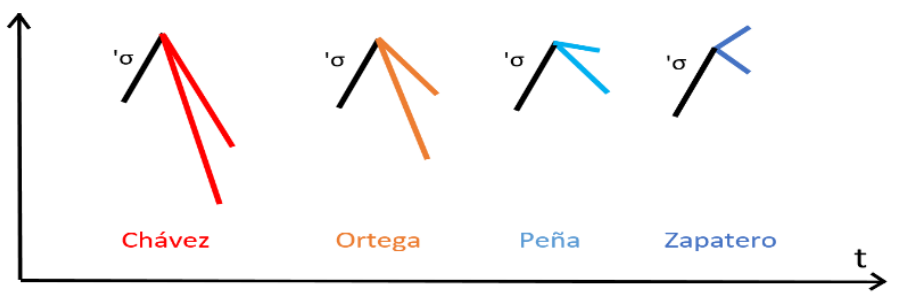

Figure 5. Common realization of the final IP contour (stressed ' $\sigma+$ unstressed syllable).

\section{References}

Duez, D., 1997. Acoustic markers of political power. Journal of Psycolinguistic Research, 26(6), 641-654.

Fónagy, I., 1983. La vive voix. Essais de psycho-phonétique. Paris: Payot.

Frota, S. \& al., 2007. The phonetics and phonologie of intonational phrasing in romance. Current issues in linguistics theory, pp. 131-154.

Léon, P., 1993. Précis de phonostylistique. Parole et expressivité: Nathan.

Martin, P., 1975. Analyse phonologique de la phrase française. Linguistics 146, pp. 3568.

Martin, P., 2010. Intonation in Political Speech: Ségolène Royal vs. Nicolas Sarkosy. Rome, pp. 54-64.

Martin, P., 2015. The structure of spoken language. Intonation in Romance: Cambridge University Press.

Rossi, M., 1971. Le seuil de glissando ou le seuil de perception des variations tonales pour la parole. Phonetica, Volume 23, pp. 1-33.

Sosa, J. M., 1999. La entonación del Español: Su estructura fónica, variabilidad y dialectología. Madrid: Catedra.

Touati, P., 1995. Pitch range and register in french political speech. Proc. XIII International Congress of Phonetic Sciences, Volume 4, pp. 244-248. 